\title{
Procalcitonin Level Can be a Useful Indicator of When Antibiotics Should be Stepped up in Children with Cancer and Fever without Source
}

Natthaporn Chumkong, M.D., Puttichart Khantee, M.D., Kamolwish Laoprasopwattana, M.D.

Department of Pediatrics, Faculty of Medicine, Prince of Songkla University, Hat Yai, Songkhla 90110, Thailand.

Received 21 September 2020 • Revised 8 April 2021 • Accepted 21 April 2021 • Published online 13 July 2021

\begin{abstract}
:
Objective: To assess whether procalcitonin (PCT) levels can be a reliable indicator of when it is unnecessary to step up antibiotics in children with cancer and fever without source (FWS).

Material and Methods: The medical records of children with hematologic-oncologic malignancies aged 3 months-15 years who had FWS $\geq 4$ days and were admitted to Songklanagarind Hospital from December 2016 to February 2019 were reviewed.

Results: FWS was identified in 89 patients. PCT levels were tested in 43 patients; 21 and 22 patients had low PCT (PCT $<0.5$ nanograms per milliliter $(\mathrm{ng} / \mathrm{mL}))$ and high PCT (PCT $\geq 0.5 \mathrm{ng} / \mathrm{mL}$ ) levels, respectively. The baseline characteristics of the patients including age, sex, risk of serious bacterial infection, and duration of antibiotic(s) among the 3 groups (low-PCT, high-PCT and PCT-not-tested) were not significantly different. The proportions of patients who had had their antibiotics stepped up after 4 days with conventional treatment were $65.0 \%, 90.9 \%$, and 95.7\% and who were stepped up to carbapenem were $38.1 \%, 68.2 \%$, and $73.9 \%$ in the low-PCT, high-PCT, and PCT-not-tested groups, respectively, significantly lowest in the low-PCT group. High PCT levels were associated with sepsis with sensitivity, specificity, positive predictive value, and negative predictive value of $87.5 \%, 57.1 \%, 31.8 \%$, and $95.2 \%$, respectively.
\end{abstract}

Conclusion: We suggest that cancer children who have FWS without sepsis and low PCT levels do not need to have their antibiotics stepped up; however, as the sample size of this study was quite small, further studies are needed to confirm our findings and conclusion.

Keywords: carbapenem, febrile neutropenia, fever without source, imipenem/meropenem, procalcitonin

Contact: Prof. Kamolwish Laoprasopwattana, M.D.

Department of Pediatrics, Faculty of Medicine,

Prince of Songkla University, Hat Yai, Songkhla 90110, Thailand.

E-mail: kamolwish@gmail.com, Ikamolwi@medicine.psu.ac.th

Hosting by Prince of Songkla University. All rights reserved.

This is an open access article under the CC BY-NC-ND license

(http://www.jhsmr.org/index.php/jhsmr/about/editorialPolicies\#openAccessPolicy).

J Health Sci Med Res 2022;40(2):173-180 doi: $10.31584 /$ jhsmr.2021826 www.jhsmr.org 


\section{Introduction}

Febrile neutropenia is a serious condition in hematologic-oncologic malignancies. The 2010 clinical practice guideline for the use of antimicrobial agents in neutropenic patients with cancer recommends empirical antibiotics that cover common organisms including Pseudomonas aeruginosa for all febrile neutropenia patients, and if fever persists for more than 4 days, the guideline recommends adjusting the antibiotic(s) and/or antifungal(s) to cover a broader spectrum of microorganisms. ${ }^{1}$

A previous study in our hospital found bacteremia in $20(9.3 \%)$ of 216 febrile neutropenic patients and gram negative bacteria were $80.0 \%$ of the identified organisms, with emerging bacteremia during treatment in only 5/216 (2.3\%) episodes. ${ }^{2}$ Therefore, giving broader antibiotics to all febrile neutropenic patients whose fever has not subsided in 4 days is not necessary in most of these patients, and unnecessary administration leads to increased risk of antibiotic resistance.

Recently, the incidence of carbapenem-resistant Enterobacteriaceae (CRE) has been increasing ${ }^{3}$, especially in febrile neutropenic children, including in the pediatric malignancy ward at Songklanagarind Hospital, since 2018. Therefore, identifying febrile neutropenic patients who are at risk of bacterial infection is important when considering adjusting antibiotics.

In patients with hematologic disorders it is difficult to distinguish bloodstream infections from aseptic causes of febrile episodes. A previous study found that clinical information scores had a low sensitivity of $46.0 \%$ in such cases. $^{4}$

Among the biomarkers commonly used for guiding antibiotic use, such as procalcitonin (PCT), interleukin (IL)6, IL-8, and C-reactive protein (CRP), PCT appears to be more discriminative than the others. ${ }^{5}$ PCT, a 116 amino acid prohormone of calcitonin, has been proven to be a useful biomarker to guide antibiotic use in several clinical conditions because it is mainly found in bacterial infections.

Previous studies in febrile neutropenic patients reported that a PCT level $\geq 0.5$ nanograms per milliliter (ng/ $\mathrm{mL}$ ) could distinguish bacterial infections from other causes of fever with sensitivities ranging from 50.0-70.0\%. ${ }^{4,6-11}$ A PCT level $<0.5 \mathrm{ng} / \mathrm{mL}$ could predict the absence of bacteremia with negative predictive (NPV) values of 69.0$90.0 \%{ }^{7,12-14}$

In addition, other studies have found that PCT levels dramatically decreased after resolution of the infection, while PCT levels elevated when the infection worsened. Notably, pronounced PCT levels were also found in patients with fever without source (FWS) who were responding to antibiotics, compared with those not responding to treatment with antibiotics. ${ }^{15,16}$ These findings provide new insights into the use of PCT levels when considering changes to antimicrobial regimens. ${ }^{15,16}$

To date, there have been only a few studies which have explored the role of PCT-guided antibiotic management in cancer children with FWS and fever persisting $\geq 4$ days, so this study was undertaken to assess the situation in our institution, a university learning hospital and the primary tertiary care and referral center in southern Thailand.

\section{Material and Methods}

Children with a hematologic-oncologic malignancy older than 3 months and less than 15 years of age who were hospitalized at Songklanagarind Hospital between $1^{\text {st }}$ December 2016 and $28^{\text {th }}$ February 2019 with one of the following (1) first episode of FWS lasting for at least 4 days, and/or (2) needing stepped-up antibiotics after the initial antibiotic due to sepsis, or having a microbiologically documented infection (MDI) or clinically documented infection (CDI), were enrolled in the study. 
Patients who were colonized with CRE, had a carbapenem drug allergy, were initially treated with carbapenems, or were initially diagnosed as MDI or CDI were excluded.

A febrile neutropenia episode was defined as a body temperature $(\mathrm{BT}) \geq 38.3$ degrees Celsius once or $\geq 38$ degrees Celsius on two or more occasions at least one hour apart during a 12-hour period with an absolute neutrophil count (ANC) $\leq 1,000$ cells per cubic milliliter $\left(\right.$ cells $\left./ \mathrm{mm}^{3}\right)$. High risk febrile neutropenia was defined as profound neutropenia (duration of neutropenia $>7$ days with absolute ANC $\leq 100$ cells $/ \mathrm{mm}^{3}$ ), clinical instability, or any organ failure. In the PCT-guided groups, the PCT level was tested on day 4-5 if the fever had not decreased or prior to stepping-up the antibiotic(s).

Sepsis was defined as (1) having age-based systemic inflammatory response syndrome defined as meeting $\geq 2$ of the diagnostic criteria, (2) confirmed or suspected invasive infection, and (3) having cardiovascular dysfunction, acute respiratory distress syndrome, or $\geq 2$ noncardiovascular organ system dysfunctions. Septic shock was defined as the subset of patients with cardiovascular dysfunction along with hypotension, treatment with a vasoactive medication, and/or impaired perfusion. ${ }^{17}$

Descriptive statistics [mean and standard deviation, median and interquartile range (IQR), or frequency and percentage] were used as appropriate. Comparisons among the three groups of patients were done with ANOVA. Comparisons among groups of patients used Student's t-test or Mann-Whitney U-test for normally distributed and non-normally distributed continuous variables, respectively. Chi-square or Fisher's exact test was used for comparisons of categorical data. R program for Windows was used for statistical analysis.

This study was approved by the Human Research Ethics Committee, Faculty of Medicine, Prince of Songkla University (REC. 61-408-1-4).

\section{Results}

Comparing baseline characteristics among the groups

Of a total of 200 patients with malignancy and FWS or febrile neutropenia assessed for eligibility, 89 patients met the enrolment criteria, with 46 patients and 43 patients, respectively, in the no-PCT and PCT-guided groups. The PCT-guided group was further classified into 2 subgroups based on low (PCT $<0.5 \mathrm{ng} / \mathrm{mL}$ ) and high (PCT $\geq 0.5 \mathrm{ng} /$ $\mathrm{mL}$ ) PCT levels, with 21 and 22 patients, respectively.

The baseline characteristics including sex, age, febrile neutropenia risk, chemotherapy phase, body temperature, and platelet count were not statistically significantly different between the 3 groups. The median WBCs and ANCs at admission and follow up dates in the PCT-not-tested group were significantly lower than in the other two groups. The proportions of patients with ANCs at admission and follow up date $<100$ cells $/ \mathrm{mm}^{3}$ were significantly higher in the PCT-not-tested group than in the PCT-tested groups (Table 1).

According to the inclusion criteria not including carbapenem usage as the initial empirical antibiotic, none of the enrolled patients at the initial treatment had sepsis, but 20 patients developed sepsis over the next 4-5 days. The proportion of patients with sepsis was lower in the low-PCT group (4.8\%) but not significantly different from the high-PCT (31.8\%) and PCT-not-tested (19.6\%) groups (Table 1).

Of the 20 patients who had sepsis, bacteremia was identified in 3 patients, 2 and 1 patients in the PCT-nottested and low-PCT groups, respectively. Of the 2 patients in the PCT-not-tested group, one patient had a central lineassociated bloodstream infection, for which Escherichia coli was identified and was susceptible to colistin. The minimal inhibitory concentration of meropenem was 12 micrograms/ $\mathrm{mL}$. He was treated with meropenem (120 milligrams per kilogram per day (mg/kg/day)) via continuous intravenous 
drip for 3 hours every 8 hours and colistin ( $5 \mathrm{mg} / \mathrm{kg} /$ day) via intravenous drip every 8 hours. The other patient had Klebsiella pneumoniae and Enterobacter cloacae bacteremia which was susceptible to a third generation cephalosporin. None of the 3 patients with bacteremia died.

The patient in the low-PCT group with bacteremia had a PCT level of $0.18 \mathrm{ng} / \mathrm{mL}$. After he was initially treated with ceftazidime and amikacin for 4 days, he developed clinical sepsis then meropenem and colistin were begun.
Multidrug-resistant Acinetobacter baumannii was isolated from his bloodstream, an organism fully susceptible only to colistin, intermediately susceptible to cefoperazone/ sulbactam and tigecycline and resistant to all drugs in the aminoglycoside, cephalosporin, carbapenem, and fluoroquinolone groups. He was eventually successfully treated with cefoperazone/sulbactam (300 mg/kg/day) and colistin (5 mg/kg/day).

Table 1 Patient characteristics and comparison of CBC values on first day and day $4-5$ of empirical antibiotic(s) among the 3 study groups

\begin{tabular}{|c|c|c|c|c|}
\hline \multirow[b]{2}{*}{ Variable } & \multirow{2}{*}{$\begin{array}{l}\text { PCT-not-tested } \\
(n=46)\end{array}$} & \multicolumn{2}{|c|}{ РCT-guided } & \multirow[b]{2}{*}{ p-value } \\
\hline & & $\begin{array}{l}\mathrm{PCT}<0.5 \mathrm{ng} / \mathrm{mL} \\
(\mathrm{n}=21)\end{array}$ & $\begin{array}{l}\text { РСТ } \geq 0.5 \mathrm{ng} / \mathrm{mL} \\
(\mathrm{n}=22)\end{array}$ & \\
\hline Age (years), median (IQR) & $4.8(4.4,9.7)$ & $4.3(2.1,9.5)$ & $6.9(2.7,12.2)$ & 0.452 \\
\hline Male, n (\%) & $30(65.2)$ & $13(61.9)$ & $11(50.0)$ & 0.478 \\
\hline \multicolumn{5}{|l|}{ Malignancy, n (\%) } \\
\hline Hematologic & $29(63.0)^{\mathrm{a}}$ & $16(76.2)^{\mathrm{a}}$ & $8(36.4)^{\mathrm{b}}$ & 0.020 \\
\hline Oncologic & $17(37.0)^{\mathrm{a}}$ & $5(23.8)^{\mathrm{a}}$ & $14(63.6)^{\mathrm{b}}$ & \\
\hline High risk, n (\%) & $36(78.3)$ & $10(47.6)$ & $16(72.7)$ & 0.078 \\
\hline Induction phase of chemotherapy & $15(32.6)$ & $9(42.9)$ & $5(22.7)$ & 0.481 \\
\hline Initial antibiotic(s), n (\%) & & & & 0.210 \\
\hline Ceftazidime + amikacin & $39(84.8)$ & $18(85.7)$ & $14(63.6)$ & \\
\hline Piperacillin/tazobactam & $6(13.0)$ & $3(14.3)$ & $6(27.3)$ & \\
\hline Others & $1(2.2)$ & 0 & $2(9.1)$ & \\
\hline \multicolumn{5}{|c|}{ Initial day of antibiotic(s) } \\
\hline $\mathrm{BT}{ }^{\circ} \mathrm{C}$, median (IQR) & $38.8(38.3,39.3)$ & $38.7(38.4,39.0)$ & $38.4(38.5,38.9)$ & 0.220 \\
\hline WBC $\times 10^{3}$ (cells $\left./ \mathrm{mm}^{3}\right)$, median (IQR) & $1.1(0.3,2.8)^{\mathrm{a}}$ & $3.5(0.7,9.9)^{\mathrm{b}}$ & $5.4(0.7,11.4)^{b}$ & 0.002 \\
\hline ANC $\left(\right.$ cells $\left./ \mathrm{mm}^{3}\right)$, median (IQR) & $0(0,704)^{a}$ & $1045(114,5561)^{\mathrm{b}}$ & $174(0,609)^{\mathrm{b}}$ & 0.020 \\
\hline ANC $\leq 100$ cells $/ \mathrm{mm}^{3}, \mathrm{n}(\%)$ & $27(58.7)^{\mathrm{a}}$ & $5(23.8)^{b}$ & $7(31.8)^{\mathrm{b}}$ & 0.002 \\
\hline Platelets, $\times 10^{3}\left(\right.$ cells $\left./ \mathrm{mm}^{3}\right)$, median (IQR) & $73(47,154)$ & $195(80,345)$ & $88(30,342)$ & 0.100 \\
\hline \multicolumn{5}{|c|}{$>48$ hours after antibiotic(s) begun } \\
\hline $\mathrm{BT}{ }^{\circ} \mathrm{C}$, median (IQR) & $38.8(38.5,39.2)$ & $38.7(38.2,39.3)$ & $38.7(38.2,39.6)$ & 0.498 \\
\hline Sepsis, n (\%) & $12(19.6)$ & $1(4.8)$ & $7(31.8)$ & 0.070 \\
\hline WBC $\times 10^{3}\left(\right.$ cells $\left./ \mathrm{mm}^{3}\right)$, median (IQR) & $1.0(0.5,5.7)^{\mathrm{a}}$ & $4.1(1.0,10.6)^{b}$ & $4.2(1.4,12.6)^{b}$ & 0.012 \\
\hline ANC $\left(\right.$ cells $\left./ \mathrm{mm}^{3}\right)$, median (IQR) & $0(0,821)^{a}$ & $947(215,5334)^{\mathrm{b}}$ & $607(205,7765)^{b}$ & 0.020 \\
\hline ANC $<100$ cells $/ \mathrm{mm}^{3}, \mathrm{n}(\%)$ & $29(63.0)^{a}$ & $5(23.8)^{\mathrm{b}}$ & $5(22.7)^{\mathrm{b}}$ & 0.001 \\
\hline Platelets, $\times 10^{3}$ (cells $\left./ \mathrm{mm}^{3}\right)$, median (IQR) & $62(27,192)$ & $176(33,276)$ & $113(322,298)$ & 0.260 \\
\hline
\end{tabular}

${ }^{a, b}$ Values within rows not having a superscript in common differ significantly ( $p$-value $\left.<0.050\right)$

$\mathrm{BT}=$ body temperature, IQR=interquartile range, $\mathrm{WBC}=$ white blood cells, $\mathrm{ANC}=$ absolute neutrophil count, $\mathrm{PCT}=$ procalcitonin 
Management of antibiotics and outcomes among the 3 groups whose fever had not subsided after initial empirical antibiotics $\geq 4$ days

The proportion of patients whose antibiotics were stepped up after 4 days with conventional treatment was significantly lower in the low-PCT group $(65.0 \%)$ than in the other two groups $(90.9 \%$ and $95.7 \%$ in the high- PCT and PCT-not-tested groups, respectively) (Table 2).

The proportion of patients whose antibiotics were stepped up to the carbapenem group was significantly lower in the low-PCT group (38.1\%) than the high-PCT group $(68.2 \%)$, and PCT-not-tested group (73.9\%). The median durations of total fever among the 3 groups were not significantly different (Table 2).

The mortality rates among the 3 groups were not significantly different. The only two patients with fatal outcomes were in the high-PCT group. The first fatal case died following a relapse of his acute lymphoblastic leukaemia. The second fatal case died from a progressive brain tumour with severe brain edema.

Factors associated with sepsis in children whose fever did not subside after initial empirical antibiotics $\geq 4$ days

The proportions of patients with sepsis and without sepsis were not significantly different in patients with BT $\geq 39.0^{\circ} \mathrm{C}, \mathrm{ANC}<100$ cells $/ \mathrm{mm}^{3}$, and platelets $\leq 50,000$ cells/ $\mathrm{mm}^{3}$.

Of the 43 patients who had their PCT levels tested, the proportion of patients with sepsis was significantly higher in the high-PCT group and the median PCT level was significantly higher in sepsis patients than in non-sepsis patients (Table 3$)$.

High PCT levels were significantly correlated with sepsis with sensitivity, specificity, PPV, and NPV of $87.5 \%$, $57.1 \%, 31.8 \%$, and $95.2 \%$, respectively.

Table 2 Management and outcomes among the 3 groups of children whose fever had not subsided after initial empirical antibiotics $\geq 4$ days

\begin{tabular}{|c|c|c|c|c|}
\hline \multirow[b]{2}{*}{ Variable, n (\%) } & \multirow{2}{*}{$\begin{array}{l}\text { PCT-not-tested } \\
(n=46)\end{array}$} & \multicolumn{2}{|c|}{ PCT-tested } & \multirow[b]{2}{*}{$p$-value } \\
\hline & & $\begin{array}{l}\text { PCT }<0.5 \mathrm{ng} / \mathrm{mL} \\
(\mathrm{n}=21)\end{array}$ & $\begin{array}{l}P C T \geq 0.5 \mathrm{ng} / \mathrm{mL} \\
(\mathrm{n}=22)\end{array}$ & \\
\hline Stepped-up antibiotic, n (\%) & $44(95.7)^{a}$ & $13(65.0)^{b}$ & $20(90.9)^{a}$ & 0.001 \\
\hline Carbapenem usage, n (\%) & $34(73.9)^{a}$ & $8(38.1)^{b}$ & $15(68.2)^{\mathrm{a}}$ & 0.016 \\
\hline Duration of fever (days), mean (S.D.) & $8.0(6.0,12.0)$ & $7.0(5.2,11.0)$ & $9.0(5.5,13.5)$ & 0.541 \\
\hline $\begin{array}{l}\text { Duration of fever in carbapenem usage (days), } \\
\text { mean (S.D.) }\end{array}$ & $8.0(6.0,11.0), n=34$ & $9.5(7.0,11.7), n=8$ & $9.0(6.5,16.0), n=7$ & 0.493 \\
\hline Duration of antibiotics (days), mean (S.D.) & $11.5(4.9)$ & $10.5(6.1)$ & $11.3(5.1)$ & 0.751 \\
\hline
\end{tabular}

${ }^{a, b}$ Values within rows not having a superscript in common differ significantly $(p-$ value $<0.050)$

$\mathrm{PCT}=$ procalcitonin, $\mathrm{S} . \mathrm{D} .=$ standard deviation, $\mathrm{ICU}=$ intensive care unit 
Table 3 Factors associated with sepsis in study children whose fever had not subsided after initial empirical antibiotics $\geq 4$ days

\begin{tabular}{llll}
\hline Factor & $\begin{array}{l}\text { Non-sepsis } \\
(\mathbf{n = 6 9 )}\end{array}$ & $\begin{array}{l}\text { Sepsis } \\
(\mathbf{n = 2 0})\end{array}$ & p-value \\
\hline PCT level $(\mathrm{ng} / \mathrm{mL})$, median (IQR) & $0.3(0.2,1.6), \mathrm{n}=35$ & $2.4(0.8,33.5), \mathrm{n}=8$ & 0.030 \\
PCT $\geq 0.5 \mathrm{ng} / \mathrm{mL}, \mathrm{n}(\%)$ & $15(4.9), \mathrm{n}=35$ & $7(87.5), \mathrm{n}=8$ & 0.020 \\
Body temperature $\geq 39{ }^{\circ} \mathrm{C}, \mathrm{n}(\%)$ & $25(36.2)$ & $10(50.0)$ & 0.267 \\
ANC $<100 \mathrm{cells} / \mathrm{mm}^{3}, \mathrm{n}(\%)$ & $30(43.5)$ & $9(45.0)$ & 0.904 \\
Platelets $\leq 50,000 \mathrm{cells}^{\mathrm{m}} / \mathrm{mm}^{3}, \mathrm{n}(\%)$ & $28(40.6)$ & $6(30.0)$ & 0.391 \\
\hline
\end{tabular}

$\mathrm{PCT}=$ procalcitonin, IQR=interquartile range, $\mathrm{ANC}=$ absolute neutrophil count

\section{Discussion}

Our study is the first study to demonstrate that PCT was helpful in guiding antibiotic management in cancer children whose fever persisted $\geq 4$ days after initial antibiotics. The proportion of patients who had their antibiotics stepped up was reduced from $95.7 \%$ to $65.0 \%$ and also carbapenem use decreased from $73.9 \%$ to $38.1 \%$.

We found higher sensitivity and NPV than in previous studies, which found that PCT $\geq 0.5 \mathrm{ng} / \mathrm{mL}$ had sensitivity of $50.0-70.0 \% \%^{4,6-9}$ and NPV of $69.0-90.0 \%$ to determine bacteremia., ${ }^{712-14}$ The different results in our study from these previous studies could be explained by the associated outcomes; our study focused on clinical sepsis while the others examined bacteremia. Of the 89 febrile episodes in our study, hemoculture was positive in only 3 episodes even though 20 patients had sepsis. Of the 3 patients with bacteremia, 1 had a PCT test which found $<0.5 \mathrm{ng} / \mathrm{mL}$. These findings suggest that PCT testing should not be used to guide antibiotic management in cancer patients who have sepsis or systemic inflammatory response.

The cost of PCT testing at the time of our study was 30 United States dollars per test, which was and is considered expensive in our hospital, and most physicians step-up the antibiotic in patients at high risk of bacterial infection and/or developing clinical sepsis without ordering a
PCT test. This practice could explain why we found higher proportions of patients with ANC $<100$ cells $/ \mathrm{mm}^{3}(63.0 \%$ vs $23.8 \%$ ) and who had their antibiotics stepped-up to the carbapenem group (73.9\% vs 53.5\%), respectively, in the PCT-not-tested group than the PCT-guided group.

Although we found that patients with PCT $<0.5$ $\mathrm{ng} / \mathrm{mL}$ had a low risk of developing sepsis and/or bacteremia, one case in the low-PCT group developed gram negative septicemia. Previous studies found that PCT had low sensitivity as a marker of infection in patients with neutropenic fever ${ }^{18}$ and also poor sensitivity in gram-positive infections. ${ }^{8,18}$ Taking these things together, we suggest that PCT-guided antibiotics should only be used in cancer patients with FWS and no clinical sepsis.

Although one previous study suggested that neutropenia might affect PCT levels ${ }^{18}$, we found that PCT levels were not correlated with ANC $(r=0.08, p-v a l u e=0.591)$ and the median (IQR) PCT levels in those with $A N C \geq 500$ cells $/ \mathrm{mm}^{3}$ and ANC $<500$ cells $/ \mathrm{mm}^{3}$ were not significantly different (PCT levels were $0.3(0.2,1.9)$ and $0.9(0.3,1.9)$ $\mathrm{ng} / \mathrm{mL}$, respectively), which was similar to a previous study in febrile cancer children which found no correlation of PCT levels and ANC $(r=-0.08){ }^{14}$

We found that PCT levels were significantly higher in children with sepsis (Table 3), which was also reported 
in previous studies which found that cancer patients with bacteremia, especially gram negative bacteremia or severe bacterial infection, had higher PCT levels than those without serious bacterial infection or viral infection., 811,19,20

We found as in a previous study that PCT-guided antibiotic management did not reduce the duration of required antibiotic use. ${ }^{9}$ This finding could be explained by noting that duration of antibiotic use is not influenced by PCT levels but is influenced by clinical well-being, body temperature and ANC.

The main limitation of this study was its retrospective nature, in which clinical decisions depended on the doctor's experience, their decisions concerning antibiotic management and requesting tests for other biomarkers, and their clinical judgment.

\section{Conclusion}

In this study, PCT-guided antibiotic decisions reduced carbapenem usage by $35.8 \%$. PCT-guided antibiotics should be used only in patients without clinical sepsis. Clinically-well cancer patients with FWS and persistent fever $\geq 4$ days with PCT levels $<0.5 \mathrm{ng} / \mathrm{mL}$ can be continued on their initial empirical antibiotic(s). Due to the small sample size, further studies are needed to confirm these conclusions.

\section{Acknowledgement}

The authors wish to thank David Patterson, an English teacher and consultant with the Faculty of Medicine, Prince of Songkla University, for help with the English.

\section{Conflict of interest}

This work had no financial or commercial interests.

\section{References}

1. Freifeld AG, Bow EJ, Sepkowitz KA, Boeckh MJ, Ito Jl, Mullen $\mathrm{CA}$, et al. Clinical practice guideline for the use of antimicrobial agents in neutropenic patients with cancer: 2010 Update by the Infectious Diseases Society of America. Clin Infect Dis 2011;52:e56-93

2. Laoprasopwattana K, Pruekprasert P, Laosombat V, Wongchanchailert M. Clinical outcome of febrile neutropenia in children with cancer using ceftazidime and aminoglycosides. Pediatr Hematol Oncol 2007;24:595-606.

3. Lee JH, Kim SK, Han SB, Lee JW, Lee DG, Chung NG, et al. Increase in antibiotic-resistant gram-negative bacterial infections in febrile neutropenic children. Infect Chemother 2016;48:181-9

4. Ahn S, Lee YS, Lim KS, Lee JL. Adding procalcitonin to the MASCC risk-index score could improve risk stratification of patients with febrile neutropenia. Support Care Cancer 2013; 21:2303-8.

5. Kern WV. Risk assessment and treatment of low-risk patients with febrile neutropenia. Clin Infect Dis 2006;42:533-40.

6. Giamarellou H, Giamarellos-Bourboulis EJ, Repoussis P, Galani L, Anagnostopoulos N, Grecka P, et al. Assessment of procalcitonin as a diagnostic and prognostic marker in patients with solid tumors and febrile neutropenia. Clin Microbiol Infect 2004;10:628-33.

7. Jimeno A, Garcia-Velasco A, del Val O, Gonzalez-Billalabeitia E, Hernando S, Hernandez R, et al. Assessment of procalcitonin as a diagnostic and prognostic marker in patients with solid tumors and febrile neutropenia. Cancer 2004;100:2462-9.

8. Yang M, Choi SJ, Lee J, Lee DG, Kim YJ, Park YJ, et al. Serum procalcitonin as an independent diagnostic markers of bacteremia in febrile patients with hematologic malignancies. Plos One 2019;14:e0225765.

9. Lima SS, Nobre V, de Castro Romanelli RM, Clemente WT, da Silva Bittencourt HN, Melo AC, et al. Procalcitonin-guided protocol is not useful to manage antibiotic therapy in febrile neutropenia: a randomized controlled trial. Ann Hematol 95:2016;1169-76.

10. Hatzistilianou M, Rekliti A, Athanassiadou F, Catriu D. Procalcitonin and $\mathrm{C}$-reactive protein serum levels as markers of infection in a pediatric population with febrile neutropenia and cancer. Inflamm Res 2010;59:339-47.

11. Robinson JO, Lamoth F, Bally F, Knaup M, Calandra T, Marchetti O. Elevated procalcitonin predicts Gram-negative sepsis in haematological patients with febrile neutropenia. Plos One 2011;6:0018886. 
12. Fleischhack G, Kambeck I, Cipic D, Hasan C, Bode U. Procalcitonin in paediatric cancer patients: its diagnostic relevance is superior to that of C-reactive protein, interleukin 6 , interleukin 8, soluble interleukin 2 receptor and soluble tumour necrosis factor receptor II. Br J Haematol 2000;111:1093-102.

13. Engel A, Steinbach G, Kern P, Kern WV. Diagnostic value of procalcitonin serum levels in neutropenic patients with fever: comparison with interleukin-8. Scand J Infect Dis 1999;31: 185-9.

14. Hemming V, Jakes AD, Shenton G, Phillips B. Prospective cohort study of procalcitonin levels in children with cancer presenting with febrile neutropenia. BMC Pediatr 2017;17. doi: 10.1186/s12887-016-0766-8.

15. Giamarellos-Bourboulis EJ, Grecka P, Poulakou G, Anargyrou K, Katsilambros N, Giamarellou H. Assessment of procalcitonin as a diagnostic marker of underlying infection in patients with febrile neutropenia. Clin Infect Dis 2001;32:1718-25.

16. Sakr Y, Sponholz C, Tuche F, Brunkhorst F, Reinhart K. Change of procalcitonin predicts clinical outcome of febrile episodes in patients with hematological malignancies. Infection 2008;36:396-407.

17. Weiss SL, Peters MJ, Alhazzani W, Agus MSD, Flori HR, Inwald DP, et al. Surviving Sepsis Campaign International Guidelines for the Management of Septic Shock and SepsisAssociated Organ Dysfunction in Children. Pediatr Crit Care Med 2020;21:e52-106.

18. Ruokonen E, Nousiainen T, Pulkki K, Takala J. Procalcitonin concentrations in patients with neutropenic fever. Eur J Clin Microbiol Infect Dis 1999;18:283-5.

19. Hitoglou-Hatzi S, Hatzistilianou M, Gougoustamou D, Rekliti A, Agguridaki C, Athanassiadou F, et al. The predictive and diagnostic values of procalcitonin and $\mathrm{C}$-reactive protein for clinical outcome in febrile neutropenic patients. Clin Exp Med 2005;5:60-5.

20. van der Galien HT, Loeffen EAH, Miedema KGE, Tissing WJE. Predictive value of PCT and IL-6 for bacterial infection in children with cancer and febrile neutropenia. Support Care Cancer 2018;26:3819-26. 